\title{
Influence of Temperature on Mechanical Properties, Fracture Morphology and Strain Hardening Behavior of a 304 Stainless Steel
}

\author{
Guilherme Corrêa Soares ${ }^{a}$, Mariana Carla Mendes Rodrigues ${ }^{a}$, Leandro de Arruda Santos $^{a *}$ \\ a Departamento de Engenharia Metalúrgica e de Materiais, Escola de Engenharia, Universidade \\ Federal de Minas Gerais. Av. Pres. Antônio Carlos, 6627 - Pampulha, Belo Horizonte, MG, \\ Brazil, 31270-901.
}

Received: December 07, 2016; Accepted: May 16, 2017

\begin{abstract}
The strain hardening behavior of an AISI 304 stainless steel at different temperatures was investigated in this work. Specimens were tensile tested up to rupture at temperatures of 25, 50, 75, 100,125 and $150^{\circ} \mathrm{C}$ by using a universal testing machine with an attached environmental test chamber. The induction of martensite by strain was assessed by X-ray diffraction and Rietveld refinement. The resultant fracture morphologies were analyzed by scanning electron microscopy. The changes in the mechanical properties as a function of temperature were evaluated through the variations in the stress-strain curve and the strain hardening behavior was described in terms of strain hardening rate, instantaneous strain hardening exponent and Crussard-Jaoul analysis. Six strain hardening stages were detected at lower temperatures, transitioning into three strain hardening stages at higher temperatures. Fracture surface was ductile at all studied temperatures, although differences in terms of dimple and void morphology were observed.
\end{abstract}

Keywords: AISI 304 steel; Strain hardening behavior; Instantaneous strain hardening exponent; Crussard-Jaoul analysis; Fracture morphology

\section{Introduction}

High strength, good formability and toughness are fundamental properties demanded by steels that are usually employed as structural materials, in areas that range from the automotive to the construction industries. Amongst those steels, the metastable austenitic stainless steels stand out for exhibiting good mechanical properties and excellent corrosion resistance $\mathrm{e}^{1,2}$.

The austenitic stainless steels have a low stacking fault energy (SFE) and the strain-induced $\varepsilon$ and $\alpha^{\prime}$ martensitic transformations play a strong role in the mechanical behavior of these materials. The formation of $\varepsilon$ martensite and $\alpha$ ' martensite, which have hexagonal close-packed and body-centered cubic atomic structures respectively, can occur upon straining and its extent is strongly affected by various factors, such as steel chemical composition, amount of plastic deformation, strain rate, strain state, deformation temperature and the grain size of the austenitic phase $\mathrm{e}^{3,4}$

Considering that metastable austenitic stainless steels cannot be hardened by heat treatments ${ }^{5}$, the occurrence of strain-induced martensitic transformation (SIMT) is an essential factor, considering that it improves the strain hardenability of the steel. The formation of $\alpha$ ' martensite is highly influenced by the SFE and the chemical driving force to transform austenite to martensite. Since both parameters are dependent on temperature, this variable also affects

* e-mail: leandro.arruda@demet.ufmg.br
$\mathrm{SIMT}^{6,7}$. There are already some works on the technical literature dealing with the sensitivity of strain hardening to temperature. In most of these works, authors have found that at a given strain, the extent of SIMT continuously decreases until being completely suppressed in response to the temperature increase. This is related to the rise in SFE and the decrease in chemical driving force ${ }^{2,3,8-10}$. Huang et $a .^{8}$ verified that there is a transition from sigmoidal to parabolic in the stress-strain curves with the increase in deformation temperature. These authors observed that the rate of martensite formation and ultimate tensile strength decrease with temperature increase, despite yield strength being relatively insensitive to temperature. Likewise, Talonen et al. ${ }^{2}$ also pointed out some changes in the stress-strain curves shape under deformation temperature variation. Those authors stated that the maximum transformation rate was reached when the volume fraction of $\alpha^{\prime}$ martensite was between $30 \sim 40 \%$ at all analyzed temperatures. Above this level, there might have been an increase in the steel work hardening due to the clustering and percolation of $\alpha$ ' martensite variants

Thus, understanding the role of deformation temperature in strain hardening is essential for the enhancement of forming parameters and mathematical modeling of such processes. Nevertheless, few studies explored the influence of deformation temperature on the AISI 304 instantaneous strain hardening exponent and on its fracture aspects under different temperatures. The aim of the present work was then to investigate the influence of temperature on the instantaneous 
strain hardening behavior and related aspects, contributing to a better understanding of the mechanisms involved in the plastic deformation of an AISI 304 stainless steel.

\section{Materials and Methods}

\subsection{Experimental}

The material used in this work was an austenitic AISI 304 stainless steel, whose chemical composition, provided by the manufacturer, is shown in Table 1 .

Uniaxial tensile tests up to rupture were carried out using an Instron 5582 universal testing machine (Instron, Norwood, MA, USA) equipped with an environmental test chamber (Instron 3119-009, Instron, Norwood, MA, USA). The tests were conducted at a strain rate of $1 \times 10^{-3} \mathrm{~s}^{-1}$ and temperatures of $25,50,75,100,125$ and $150{ }^{\circ} \mathrm{C}$. Three tests were performed per condition in order to guarantee the reliability of the measurements. Tensile test specimens were prepared according to ASTM A370 standard ${ }^{11}$, having 200x20x1mm dimensions.

Samples were cut from the tested specimens prior and after strained to a certain amount of deformation. These samples were analyzed by X-ray diffraction (XRD) in order to characterize the microstructural changes as a function of the deformation. XRD measurements were performed at room temperature in a PANanalytical PW1710 diffractometer (PANanalytical, Almelo, The Netherlands), using $\mathrm{Cu} \mathrm{K \alpha}$ radiation and Bragg-Brentano geometry. The parameters used for the XRD measurements were as follows: $35 \mathrm{kV}$ voltage; $50 \mathrm{~mA}$ anode current; diffraction angle from 20 to $90^{\circ} 2 \theta$; step size of $0.02^{\circ} 2 \theta$ and exposure time of 2.5 seconds per step. Crystalline phases were indexed by means of standard $\mathrm{X}$-ray diffraction patterns acquired from the Inorganic Crystal Structure Database (ICSD) ${ }^{12}$. Phase quantification was performed through Rietveld refinement by using the GSAS software and EXPGUI interface. It is important to point out that the samples for XRD analysis were cut from the region of homogeneous deformation in the strained specimens, thus the microstructural changes observed through XRD occurred up to the ultimate tensile strength only.

The fracture surfaces were assessed by scanning electron spectroscopy (SEM) by using an Inspect S50 microscope (FEI Company, Brno, Czech Republic) with a secondary electron detector operating at $15 \mathrm{kV}$.

\subsection{Mechanical analyses}

Based on the tensile test results, average stress-strain and flow curves for each condition were calculated for the subsequent strain hardening analyses. Mechanical properties were assessed in terms of yield strength, ultimate tensile strength, uniform elongation and average strain hardening exponent. These results and those of the strain hardening analyses were represented with their corresponding standard error of the mean.

Strain hardening stages were distinguished using a modified Crussard-Jaoul (C-J) analysis, which exhibits clearer distinction between stages than other analyses ${ }^{13-17}$. This analysis is based on the logarithmic form of Swift equation differentiated with respect to $\varepsilon$ and is given by:

$$
\operatorname{In}(d \sigma / d \varepsilon)=(1-m) \operatorname{In} \sigma-\operatorname{In}(C . m)
$$

Where $m$ is the C-J strain hardening exponent, $C$ is the strength coefficient, $\sigma$ is the true stress and $\varepsilon$ is the true strain. $(d \sigma / d \varepsilon)$ is the strain hardening rate while $(1-m)$ is the slope of $\ln (d \sigma / d \varepsilon)$ vs. $\ln \sigma$ plot.

The strain hardening rate and the instantaneous strain hardening exponent, $n_{\mathrm{i}}$, were utilized to analyze the strain hardening capability of the material. Since the strain hardening exponent is not constant, $n_{\mathrm{i}}$ is preferable to an average strain hardening exponent ${ }^{18}$. The instantaneous strain hardening exponent is given by:

$$
n_{i}=d(\ln \sigma) / d(\ln \varepsilon)
$$

\section{Results}

\subsection{Mechanical properties}

Figure 1 shows the tensile test results for the AISI 304 samples strained at $25,50,75,100,125$ and $150^{\circ} \mathrm{C}$. Figure 1a presents the stress-strain curves and Figure $1 \mathrm{~b}$ presents the flow curves that were employed in the subsequent strain hardening analyses, which are presented in detail in section 3.4.

Figure 2 presents the values of yield strength (YS), ultimate tensile strength (UTS), uniform elongation (UE) and average strain hardening exponent $(n)$ as a function of test temperature.

\subsection{X-Ray diffraction}

XRD results showed that prior to deformation, samples exhibited completely austenitic structure, with a noteworthy preferential orientation of the $\{200\}$ and $\{220\}$ planes. Figure $3 a$ presents the experimental XRD patterns and respective Rietveld refinement for the AISI 304 samples strained up to UTS at different temperatures. The XRD analysis showed a wide variation in terms of proportional $\alpha$ ' martensite and austenite from one straining temperature to another, confirming the

Table 1. Chemical composition of the studied AISI 304 stainless steel (wt. \%).

\begin{tabular}{cccccccccc}
\hline Steel & $\mathrm{C}$ & $\mathrm{Mn}$ & $\mathrm{Si}$ & $\mathrm{P}$ & $\mathrm{S}$ & $\mathrm{Cr}$ & $\mathrm{Ni}$ \\
\hline AISI 304 & 0.043 & 0.004 & 0.36 & 0.025 & 0.002 & 18.1 & 8.0 & 0.002 \\
\hline
\end{tabular}



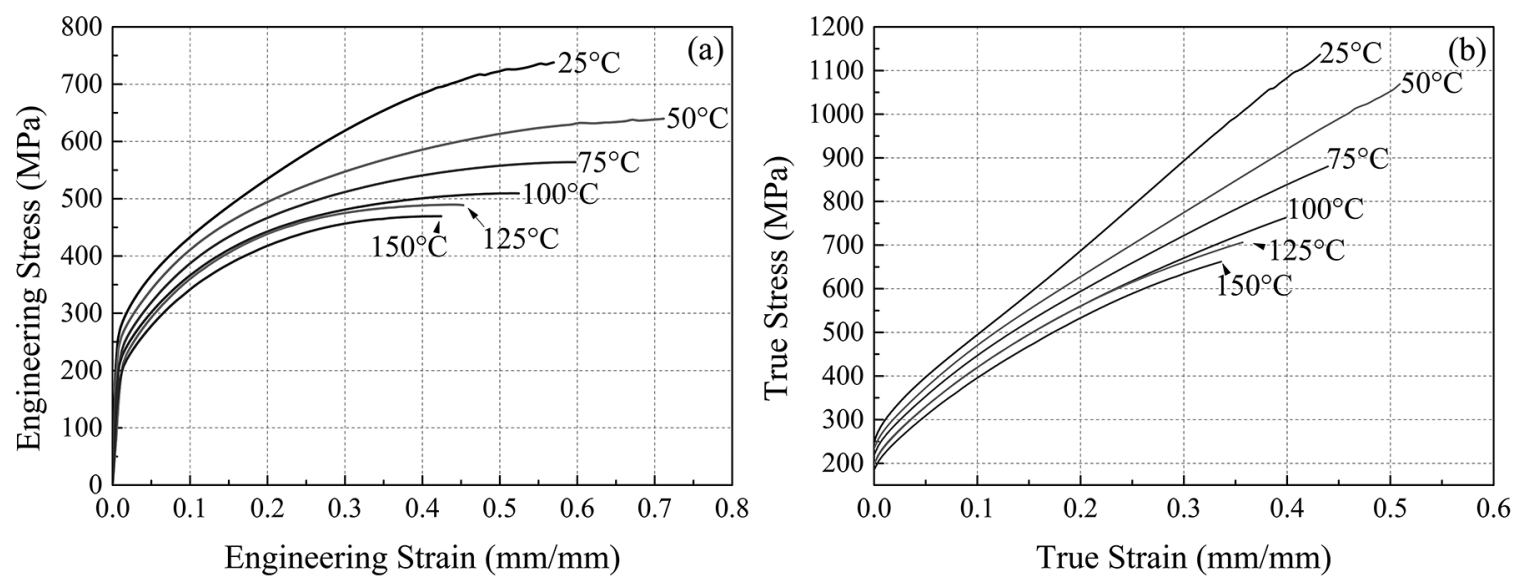

Figure 1. Engineering stress-strain curves (a) and flow curves (b) of a stainless AISI 304 steel strained at $25,50,75,100,125$ and $150^{\circ} \mathrm{C}$ at a fixed strain rate of $10^{-3} \mathrm{~s}^{-1}$.
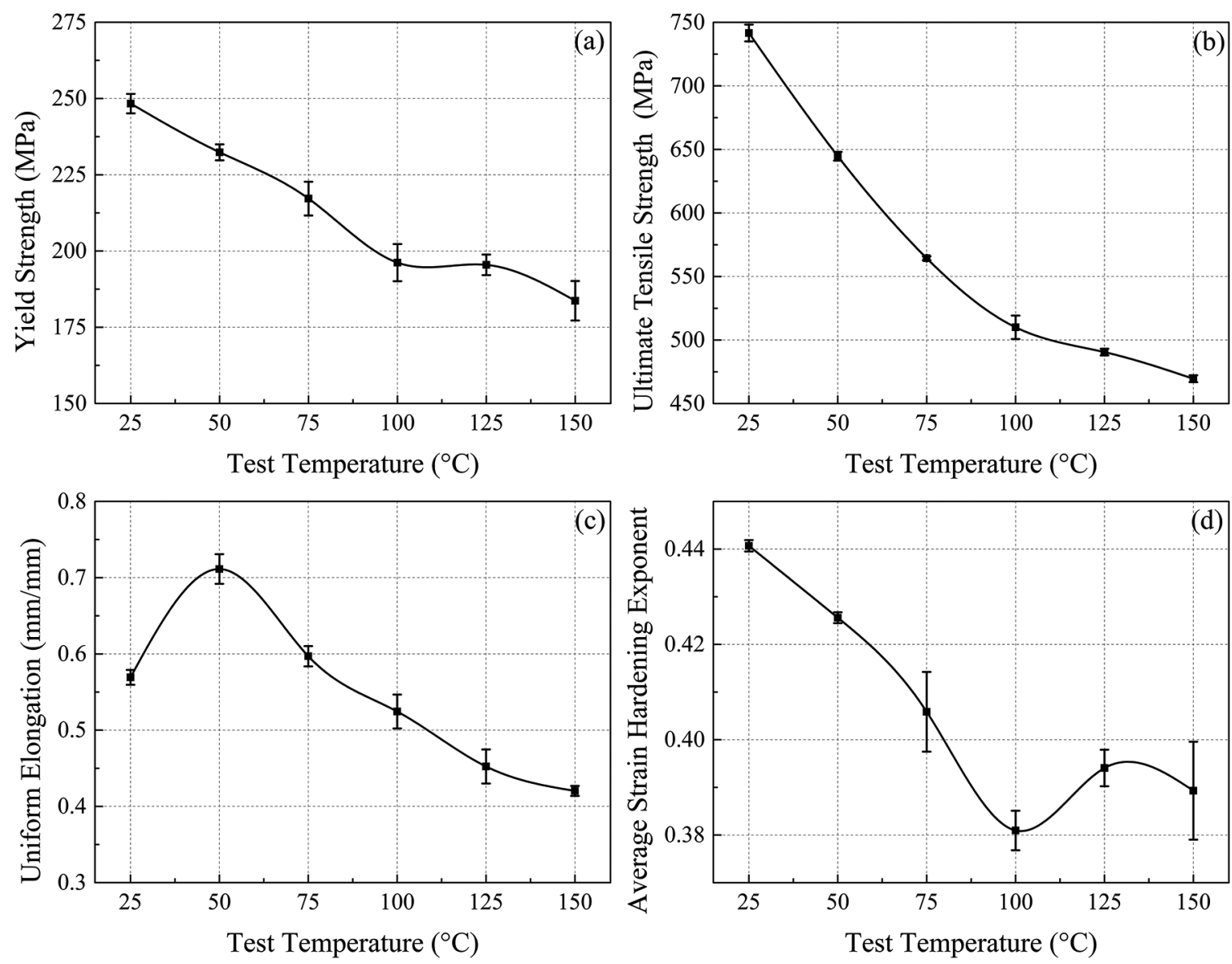

Figure 2. Yield strength (a), ultimate tensile strength (b), uniform elongation (c) and average strain hardening exponent (d) of a stainless AISI 304 steel determined in tensile testing as a function of test temperature. 
great influence of temperature on the deformation process and consequent microstructural evolution of the AISI 304 steel. The calculated $\alpha$ ' weight fraction on the samples after strained up to UTS as a function of test temperature is shown in Figure 3b. Rietveld refinement and phase quantification were not carried out on the samples strained at 125 and $150^{\circ} \mathrm{C}$, as only the austenitic phase was identified on the respective XRD patterns. The $\alpha$ ' martensite weight fraction, weighted profile R-factor $\left(R_{w p}\right)$ and goodness of fit $\left(\chi^{2}\right)$ associated with the Rietveld refinement are presented in Table 2. According to the literature ${ }^{19,20}$, acceptable $R_{w p}$ and $\chi^{2}$ values should be approximately $10 \%$ and 1 , respectively. $R_{w p}$ and $\chi^{2}$ for the samples tested 25 and $50{ }^{\circ} \mathrm{C}$ fit these conditions and corroborate with the refinement, however, as a result of the remarkably low $\alpha$ ' martensite fraction at samples tested at 75 and $100{ }^{\circ} \mathrm{C}$, these parameters have diverted from what would be considered optimal.
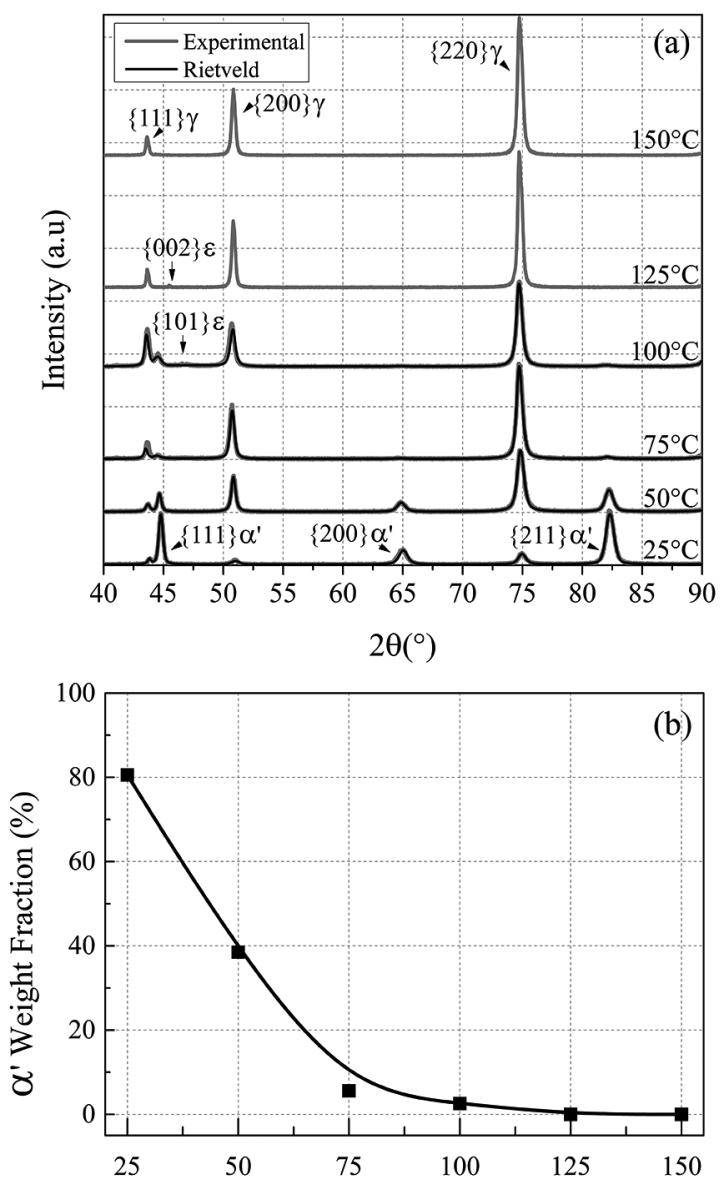

Test Temperature $\left({ }^{\circ} \mathrm{C}\right)$

Figure 3. (a) XRD patterns (gray lines) and Rietveld refinement analysis (black lines) for the AISI 304 steel samples after strained up to UTS at $25,50,75,100,125$ and $150^{\circ} \mathrm{C}$. Austenite peaks are identified by $\gamma, \alpha$ ' martensite peaks by $\alpha$ ' and $\varepsilon$ martensite peaks by $\varepsilon$. (b) $\alpha$ ' weight fraction as a function of test temperature.
Table 2. Quantitative analyses results and parameters from Rietveld refinement of deformed AISI 304 steel samples.

\begin{tabular}{cccc}
\hline$T\left({ }^{\circ} \mathrm{C}\right)$ & $\alpha$ 'Weight Fraction $(\%)$ & $R_{w p}(\%)$ & $\chi^{2}$ \\
\hline 25 & 80.6 & 12.88 & 1.428 \\
50 & 38.5 & 12.26 & 1.437 \\
75 & 5.6 & 16.00 & 2.453 \\
100 & 2.6 & 18.67 & 3.480 \\
\hline
\end{tabular}

Low intensity $\varepsilon$ martensite reflections were detected in samples strained up to UTS at 100 and $125^{\circ} \mathrm{C}$ (see Figure $3 \mathrm{a}$ ). In addition, weak $\varepsilon$ martensite reflections were also observed in samples deformed to intermediary strain values $(\varepsilon=0.1$ and 0.2 ) at 25 and $50^{\circ} \mathrm{C}$. Figure 4 presents the most clear $\varepsilon$ martensite reflections, which were observed in the samples deformed at $25^{\circ} \mathrm{C}$ up to $\varepsilon=0.1$. In order to make the low $\varepsilon$ martensite evident in Figure 4, intensity values are displayed in a square root scale. As a result of solely low intensity reflections of $\varepsilon$ martensite being observed, no effort was done in trying to perform a quantitative analysis of this phase.

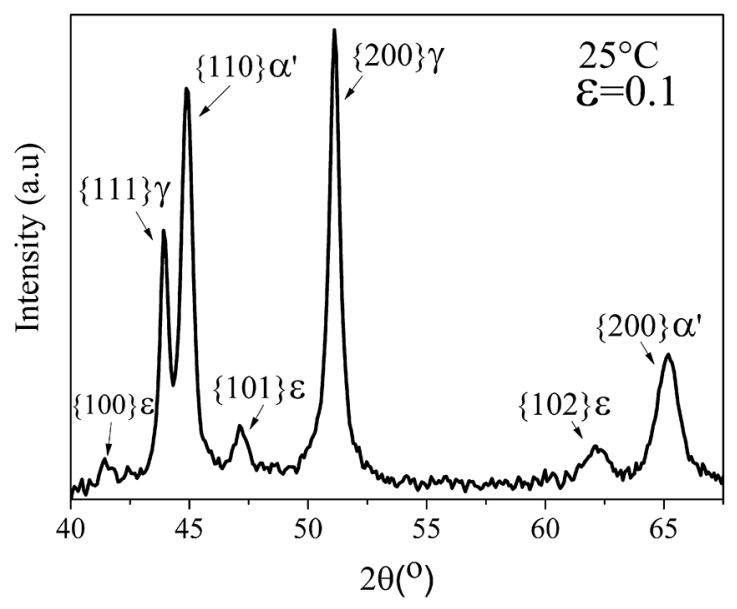

Figure 4. XRD pattern of AISI 304 steel sample after strained to $\varepsilon=0.1$ at $25^{\circ} \mathrm{C}$. Intensity values are represented in a square root scale, in order to make the $\{100\},\{101\}$ and $\{102\} \varepsilon$ martensite reflections evident.

\subsection{Fracture morphology}

Figure 5 shows an SEM macrostructure overview of the fracture morphology of the samples strained at all studied temperatures. Figure 6 shows SEM images of the fracture of the samples strained at 25,75 and $150{ }^{\circ} \mathrm{C}$. A typical ductile fracture was observed at all studied temperatures.

\subsection{Strain hardening behavior}

Figure 7 presents the $\ln (d \sigma / d \varepsilon)$ vs. $\ln (\sigma)$ plots of the modified C-J analysis in order to feature the different strain 

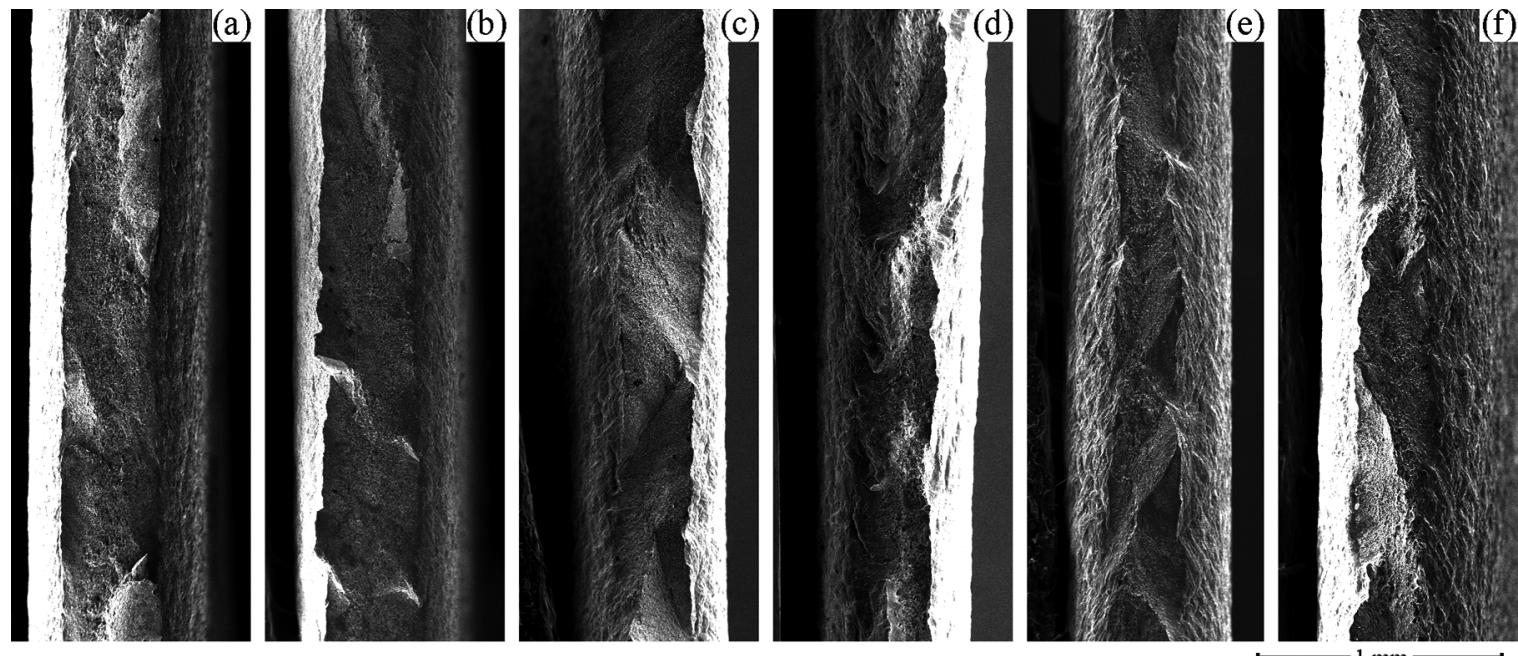

Figure 5. SEM images on a macro scale of the tensile test fracture surface of AISI 304 samples tested at $25^{\circ} \mathrm{C}(\mathrm{a}), 50^{\circ} \mathrm{C}(\mathrm{b}), 75^{\circ} \mathrm{C}(\mathrm{c})$, $100^{\circ} \mathrm{C}(\mathrm{d}), 125^{\circ} \mathrm{C}(\mathrm{e})$ and $150^{\circ} \mathrm{C}(\mathrm{f})$.

hardening stages for the AISI 304 samples strained at 25, $50,75,100,125$ and $150^{\circ} \mathrm{C}$. Figure 8 and Figure 9 show, respectively, the strain hardening rate (SHR) and instantaneous strain hardening exponent of the AISI 304 samples at the studied temperatures. For the sake of comparison, the average strain hardening exponent is also represented in Figure 9.

\section{Discussion}

\subsection{X-Ray diffraction}

XRD results clearly show the severe suppression of the $\alpha$ ' SIMT with the increase in the test temperature, as the XRD patterns change from a combination of $\alpha$ ' martensite and austenite at lower temperatures to a mainly austenitic microstructure at 125 and $150^{\circ} \mathrm{C}$. Phase quantification results show that $\alpha$ ' SIMT is a crucial strain hardening mechanism at 25 and $50{ }^{\circ} \mathrm{C}$, as the microstructure is, respectively, 80 and $38.5 \%$ martensitic after strained, and that $\alpha^{\prime}$ SIMT is completely suppressed at the $100-125^{\circ} \mathrm{C}$ range, which is in accordance with the literature ${ }^{2,7}$. Talonen et al. ${ }^{2}$ estimated that the formation of shear bands on a similar metastable austenitic steel would completely cease at $95^{\circ} \mathrm{C}$, and therefore the nucleation of $\alpha$ ' martensite, as it nucleates at shear bands intersections. Shear bands are planar defects formed by the dissociation of perfect dislocations to partial dislocations and the overlapping of stacking faults on austenite $\{111\}$ planes. $\varepsilon$ martensite, mechanical twins and faulted austenite/ $\varepsilon$ martensite are examples of planar defects that can be referred to as shear bands ${ }^{2,7}$.

XRD results of samples deformed at 25 and 50 revealed that $\varepsilon$ martensite was an intermediary phase for the formation of $\alpha^{\prime}$ martensite. Therefore, it must have influenced the strain hardening behavior of early strain stages at lower temperatures, as it is mentioned in the literature ${ }^{3,9,10,21,22}$. Low intensity $\varepsilon$ martensite reflections were observed from the samples deformed at 100 and $125^{\circ} \mathrm{C}$, indicating that albeit suppressed, the formation of shear bands still occurred at these temperatures.

\subsection{Mechanical properties}

Mechanical properties generally decreased with an increase in deformation temperature, as a result of an increase in SFE, which affected stress and strain increments related to SIMT $\mathrm{SI}^{23,6,8,9,21,23}$. The rate of decline was higher in the 25$100{ }^{\circ} \mathrm{C}$ range, as a consequence to the suppression of the SIMT. At 125 and $150^{\circ} \mathrm{C}$ this decline occurred at a lower rate and it is associated with the influence of SFE growth on dislocation glide and substructure formation ${ }^{8}$.

Nonetheless, a maximum in uniform elongation was observed at $50^{\circ} \mathrm{C}$, which is explained by a higher amount of strain induced $\varepsilon$ martensite being formed and $\alpha$ ' martensite occurring at a wider strain range, causing a more gradual increase in flow stress at high strains ${ }^{8,21}$. This increase in $\varepsilon$ martensite formation at a specific temperature range is related to the increase in SFE assisting dislocation cross-slip, and hence facilitating $\varepsilon$ martensite formation ${ }^{22}$. Considering that mechanical twinning is an active strain hardening mechanisms at intermediate SFEs, there is also the possibility of this behavior being connected to mechanical twinning prior to completely shifting to dislocation glide $6,7,9,10,21,23$.

A slight increase in the average strain hardening exponent was also observed at $125^{\circ} \mathrm{C}$. This could however be related to this not being the best parameter to describe strain hardening of materials with a more complex behavior ${ }^{18}$.

Although it is stated in the literature that yield strength of fcc metals exhibit a low temperature sensitivity 6,8, it demonstrated a decreasing behavior with temperature in this investigation, which is in accordance with preceding publications ${ }^{2,22}$. 

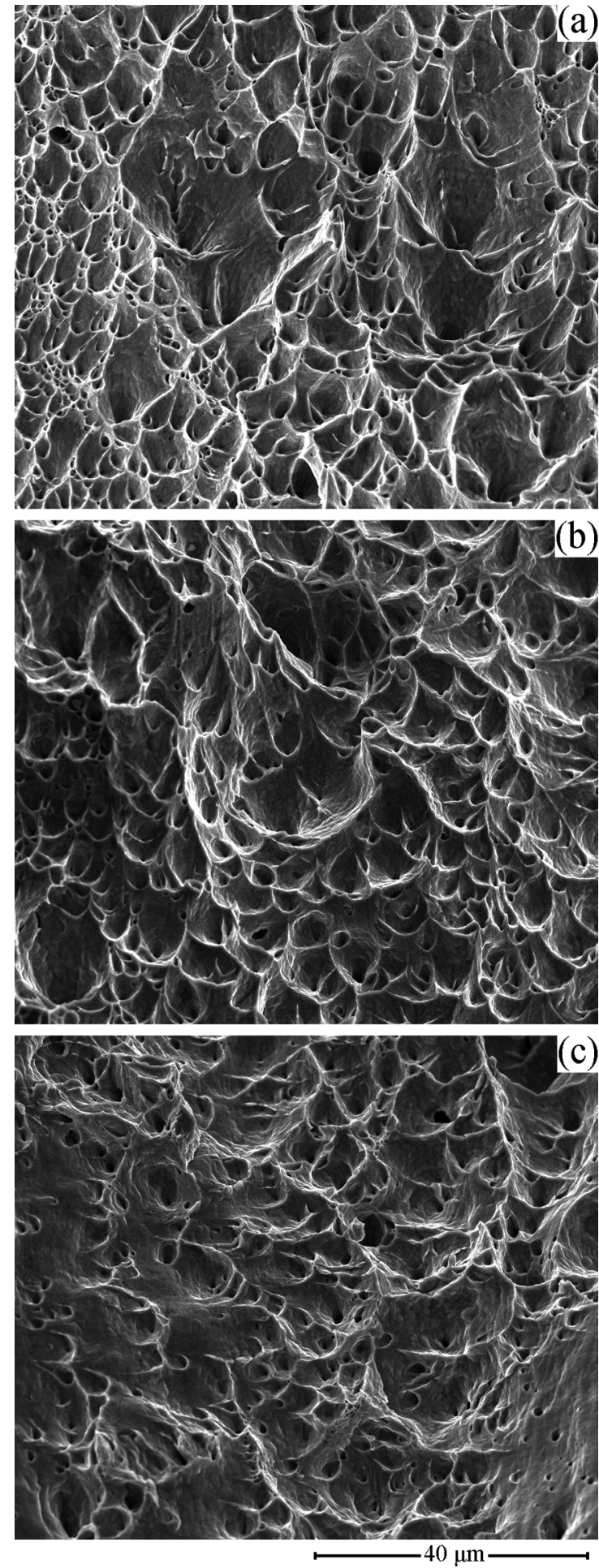

Figure 6. SEM images of ductile tensile test fracture surface of AISI 304 samples tested at $25^{\circ} \mathrm{C}(\mathrm{a}), 75^{\circ} \mathrm{C}(\mathrm{b})$ and $150^{\circ} \mathrm{C}$ (c).

\subsection{Fracture morphology}

On a macroscopic scale, temperature increment changed fracture surface from a flat profile at $25{ }^{\circ} \mathrm{C}$ to one with an edge like profile with an ever increasing number of
$\mathrm{V}$-shaped troughs, which are associated to the propagation of micro-cracks being driven in various directions. At lower temperatures $\left(25\right.$ and $\left.50^{\circ} \mathrm{C}\right)$, dynamic strengthening occurred during necking as a result of the SIMT. However, the increase in deformation temperature inhibited this local strengthening and favored the formation of micro-cracks in different directions and the emergence of such special fracture patterns ${ }^{8,24}$.

Fractographic images revealed a ductile profile at all studied deformation temperatures. The mechanisms related to ductile fracture are closely related to the nucleation, growth and coalescence of microvoids. Void nucleation occurs by decohesion of the austenitic-martensitic interface or localized deformation of the martensitic phase. Thus, the absence of large dimples at $150{ }^{\circ} \mathrm{C}$ is related to the suppression of martensite at high temperatures ${ }^{25,26,27}$.

Dimple morphology developed from large round dimples surrounded by a network of fine dimples at lower temperatures to a combination of smaller round and parabolic shear dimples at $150^{\circ} \mathrm{C}$. At higher temperatures, the inhibition of the $\alpha$ ' strain-induced transformation reduces the amount of void nucleation sites, thus reducing dimple nucleation and growth opportunity. The observed network of smaller dimples present at lower temperatures also corroborate with martensite acting as void nucleation site ${ }^{26,28}$. Additionally, the parabolic shear dimples observed at higher temperatures seemingly emerge from in-plane shear plastic fracture occurring between the formed V-shaped troughs ${ }^{25,29}$.

Despite only a qualitative analysis of dimple size have being approached in this investigation, dimple size, UTS, YS and UE followed a similar decreasing trend, as reported in the literature ${ }^{26}$. The average strain hardening exponent also seemingly followed a similar behavior.

\subsection{Strain hardening behavior}

It is noteworthy that variation in SHR and $n_{\mathrm{i}}$ in stage 1 for all studied temperatures is similar, thus, most probably not related to the SIMT. According to previous publications ${ }^{4,7,8,9,14}$, solely traces of dislocation tangles and narrow planar defects were observed at lower strain values $(\varepsilon=0.05)$, and therefore stage 1 is plausibly related to dynamic strain softening and interaction of mobile dislocations.

Stage 2's strain hardening mechanisms is seemingly similar for samples deformed at $25^{\circ} \mathrm{C}$ and $50^{\circ} \mathrm{C}$, range in which according to $\mathrm{XRD}$ results and the literature ${ }^{3,4,10,22}$, the formation of $\varepsilon$ martensite is favored and reaches a maximum at low strain values. In a previous study ${ }^{7}$, parallel shear bands formation were found to occur after a certain critical stress level was reached, which is in accordance with $\varepsilon$ martensite formation starting in stage 2. XRD data revealed traces of $\alpha$ ' martensite at $75^{\circ} \mathrm{C}$ and traces of $\varepsilon$ martensite at 100 and $125^{\circ} \mathrm{C}$, therefore, the formation of $\varepsilon$ martensite certainly contributes to strain hardening in stage 2 at these temperatures, in conjunction with dislocation glide. Despite this potential 

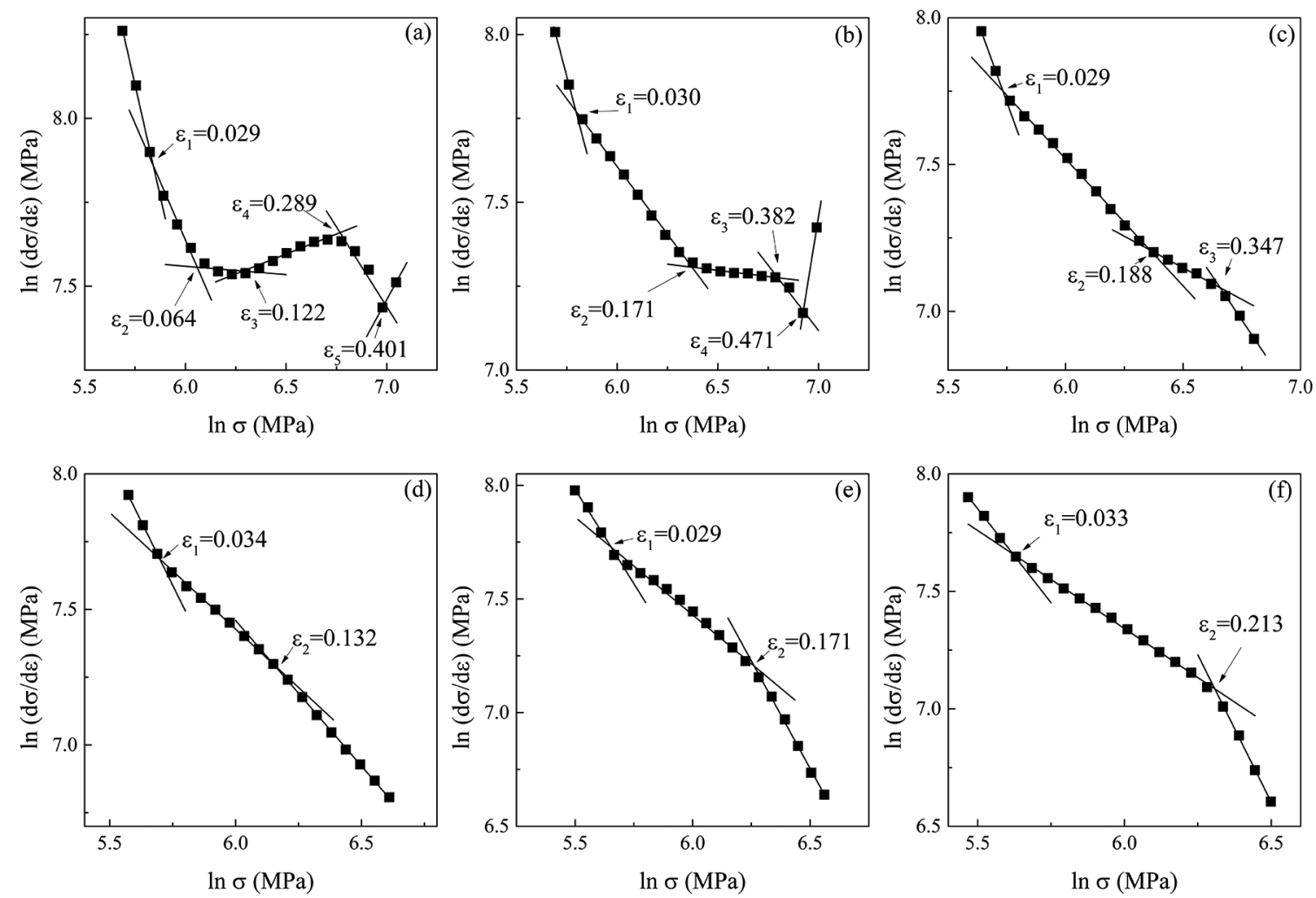

Figure 7. $\ln (\mathrm{d} \sigma / \mathrm{d} \varepsilon)$ vs. $\ln (\sigma)$ plots for strain hardening stages distinction via modified C-J analysis of AISI 304 steel samples strained at $25^{\circ} \mathrm{C}(\mathrm{a}), 50^{\circ} \mathrm{C}(\mathrm{b}), 75^{\circ} \mathrm{C}(\mathrm{c}), 100^{\circ} \mathrm{C}(\mathrm{d}), 125^{\circ} \mathrm{C}(\mathrm{e})$ and $150^{\circ} \mathrm{C}(\mathrm{f})$.

contribution of SIMT at 100 and $125^{\circ} \mathrm{C}$, and considering that no SIMT occurred at $150^{\circ} \mathrm{C}$, the dominant strain hardening mechanism in stage 2 for this temperature range is presumably dislocation glide, similar to what would be observed in more stable stainless austenitic steels, such as the AISI $316^{30}$. At higher deformation temperatures, as a result of the increase in $\mathrm{SFE}$, the nucleation of perfect dislocations is preferred ${ }^{31}$, and thus deformation is characterized by dislocation interaction, pile up at grain boundaries, higher cross-slip, lower forest dislocation density, increase in mobile dislocation density and substructure formation ${ }^{22,32,33}$. As already mentioned in section 4.2, it is also possible that mechanical twinning could occur at intermediate temperatures, considering that it is a strain hardening mechanism that is active at intermediary SFE values ${ }^{6,7,9,10,21,23}$.

At lower temperatures, the intersection of $\varepsilon$ martensite functions as a nucleation site for $\alpha$ ' martensite and $\varepsilon$ martensite is observable at strain values of circa $\varepsilon=0.05 \sim 0.2^{3,7}$. The formation of a reasonable $\alpha$ ' martensite fraction and a higher number of strain hardening stages was only observed at the deformation temperatures of 25,50 and $75^{\circ} \mathrm{C}$. Thus stage 3 is plausibly related to the onset of $\alpha^{\prime}$ martensite formation, which is also in accordance with XRD results and the literature ${ }^{4,7,22}$. In this stage, strain is accommodated in the austenitic matrix and dislocation generation is enhanced due to the formation of $\alpha$ ' martensite clusters and non- homogeneous plastic deformation, resulting in a facilitated

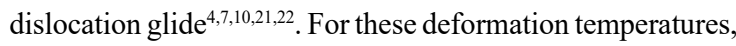
this stage exhibits a marginally diminishing SHR and an increasing $n_{\mathrm{i}}$, which is in accordance with the assumption that they are related to the same mechanism.

At $50^{\circ} \mathrm{C}$, stages 2 and 3 are clearly wider than at $25^{\circ} \mathrm{C}$, and although an increase in SHR is not observed, $n_{\mathrm{i}}$ exhibits a steady increasing behavior. Therefore, this maximum in uniform elongation at $50{ }^{\circ} \mathrm{C}$ is associated with the formation of $\varepsilon$ and $\alpha^{\prime}$ martensite over a wider strain range. A more gradual formation of martensite at $50{ }^{\circ} \mathrm{C}$ causes steady increase in flow at higher strain values and delays necking. As previously discussed in session 4.2, this occurs as a result of the increase in SFE assisting the formation of $\varepsilon$ martensite $8,21,22$.

A work hardening increase is associated with the formation of $30 \sim 40 \%$ of $\alpha$ ' martensite ${ }^{2,4}$. As this critical fraction was only achieved at the deformation at $25^{\circ} \mathrm{C}$, and that it was the only deformation temperature which presented an increase in SHR at medium strain values (stage 4 ). This stage marks the nucleation and growth of $\alpha$ ' martensite percolating clusters throughout the austenitic matrix and the $\alpha$ ' martensite plastic deformation. This microstructural evolution results in a composite strengthening effect, which further increases SHR as a consequence of its higher dislocation density ${ }^{4,5,9}$. The fact that samples deformed at 50 and $75^{\circ} \mathrm{C}$ do not reach 

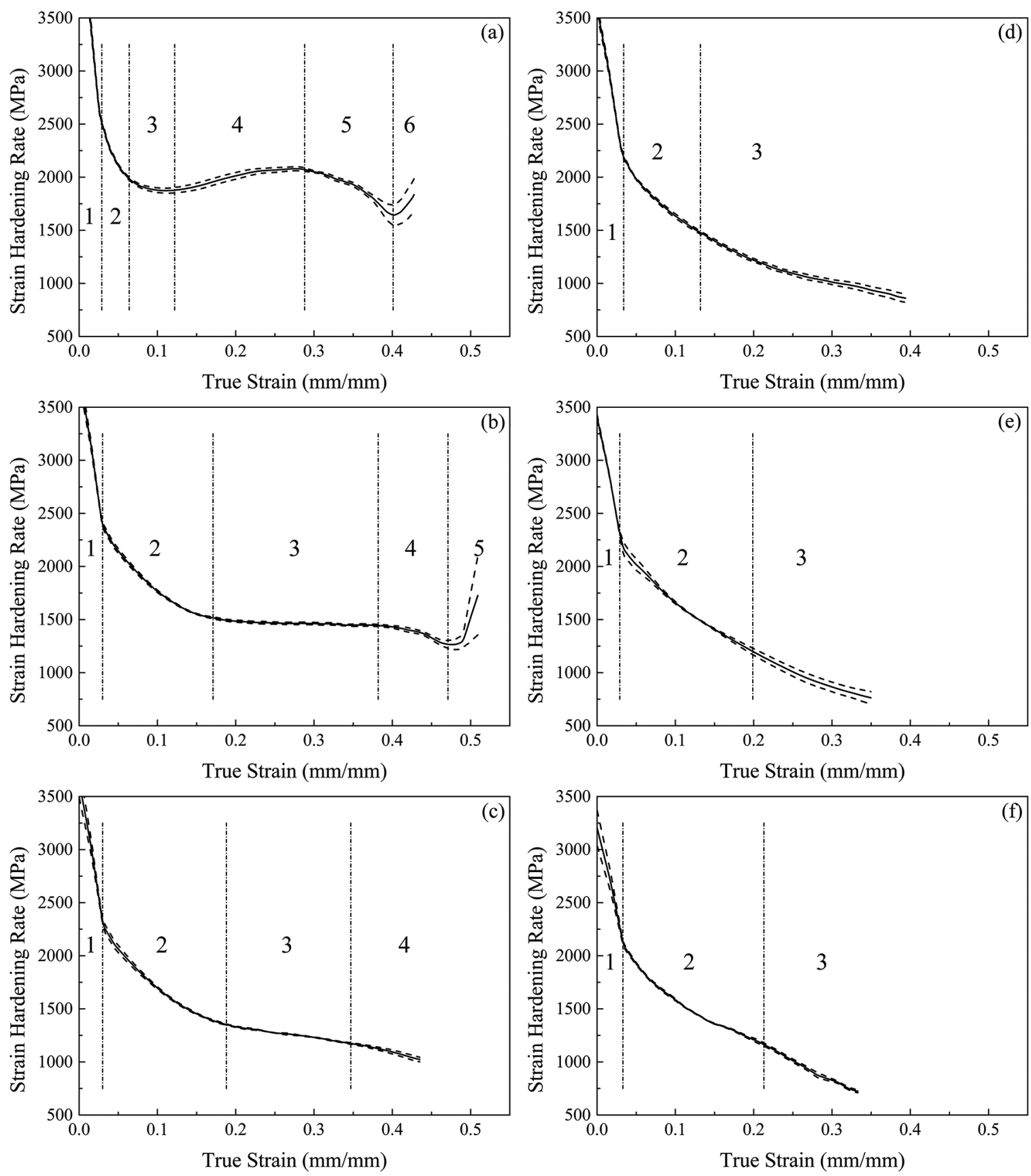

Figure 8. Strain hardening rate as a function of true strain of AISI 304 steel samples strained at $25^{\circ} \mathrm{C}(\mathrm{a}), 50^{\circ} \mathrm{C}(\mathrm{b}), 75^{\circ} \mathrm{C}(\mathrm{c}), 100^{\circ} \mathrm{C}(\mathrm{d})$, $125^{\circ} \mathrm{C}(\mathrm{e})$ and $150^{\circ} \mathrm{C}(\mathrm{f})$.

this critical $\alpha$ ' martensite fraction explains the absence of a stage featuring an increasing SHR.

Posterior stages which exhibited a decreasing behavior in SHR and $n_{\mathrm{i}}$ (i.e. $25^{\circ} \mathrm{C}$ : stage $5 ; 50$ and $75^{\circ} \mathrm{C}$ : stage 4 ; 100,125 and $150^{\circ} \mathrm{C}$ : stage 3 ) have been associated with the occurrence of dynamic recovery and the formation of highly dense dislocation walls ${ }^{4,8,9,14,22}$. It is noteworthy that stage 3's $n_{\mathrm{i}}$ predominantly increases at a deformation temperature of $100{ }^{\circ} \mathrm{C}$, which could imply that other mechanisms are active in this particular stage.
An anomalous last strain hardening with increasing SHR and $n_{\mathrm{i}}$ was observed at 25 and $50^{\circ} \mathrm{C}$. This was only observed in samples that exhibit considerable SIMT and at relatively large strains. This phenomena could perhaps be related to one of the following: 1) necking occurring at lower stress than tensile strength, dynamic formation of martensite and local strengthening happening within the neck, resulting in an post-uniform strain $^{8} ; 2$ ) the activation of strain hardening mechanisms involving a high dislocation density or possibly a complex stress state. Such increase in SHR at higher strains was also observed in previous publications ${ }^{34,35}$. 

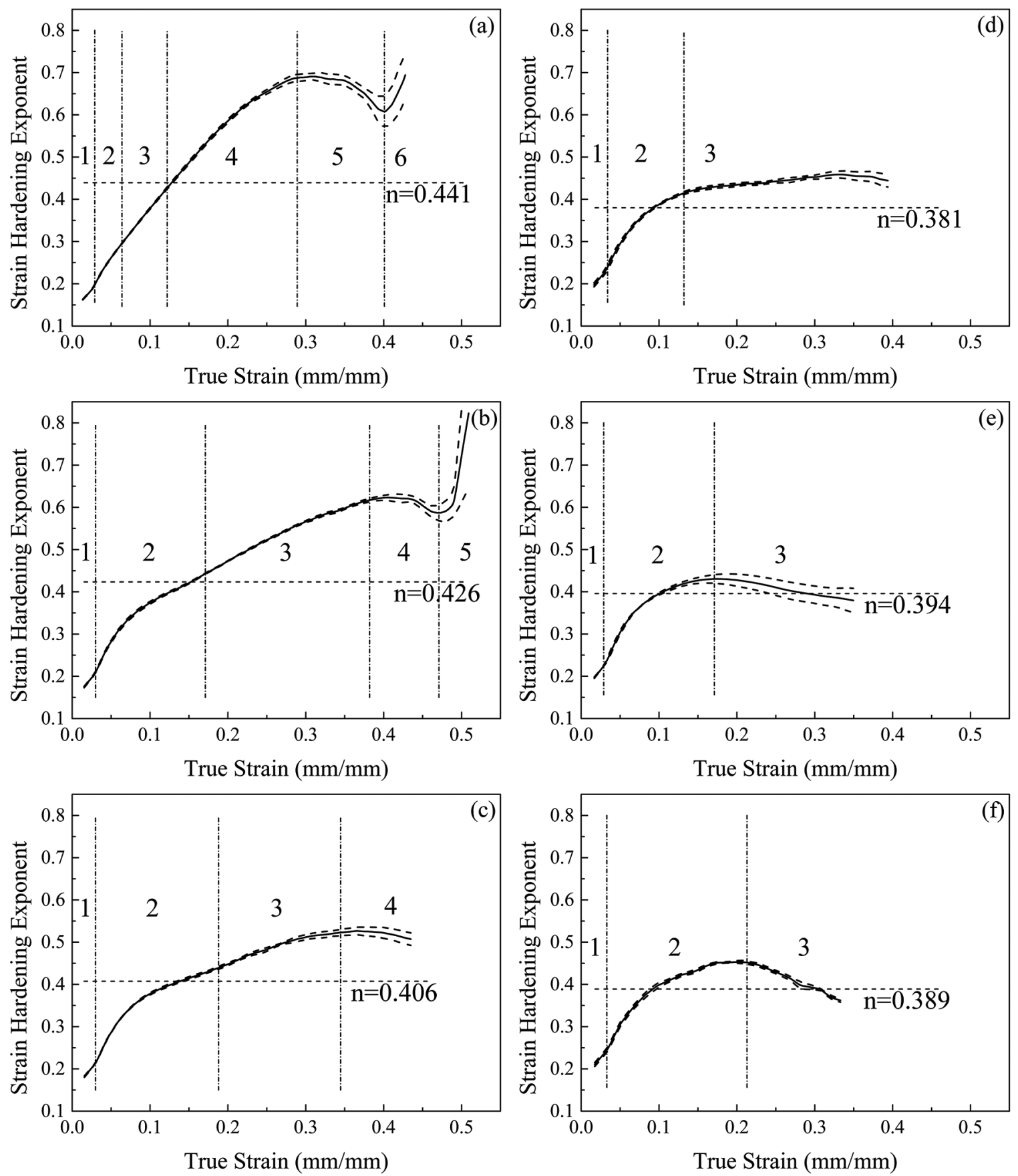

Figure 9. Instantaneous strain hardening exponent as a function of true strain and average strain hardening exponent of AISI 304 steel samples strained at $25^{\circ} \mathrm{C}(\mathrm{a}), 50^{\circ} \mathrm{C}(\mathrm{b}), 75^{\circ} \mathrm{C}(\mathrm{c}), 100^{\circ} \mathrm{C}(\mathrm{d}), 125^{\circ} \mathrm{C}$ (e) and $150^{\circ} \mathrm{C}(\mathrm{f})$.

It is evident that the average strain hardening exponent poorly represents the strain hardening exponent of the distinct strain hardening stages, as it contrasts with $n_{\mathrm{i}}$ for most of the presented deformation temperatures and stages. It is however, a good approximation of the strain hardening of the material as a whole, up to UTS. As the deformation temperature increased and the strain hardening behavior developed into a simpler one, the average strain hardening exponent displayed a better correlation with the $n_{\mathrm{i}}$ of stages 2 and 3 , which represent the majority of the respective strain hardening. Therefore, the average strain hardening exponent is a more fitting estimate for materials with less active strain hardening mechanism and a less complex mechanical behavior.

\section{Conclusions}

The strain hardening behavior and correlated mechanical properties of a AISI 304 steel at different temperatures was studied. The following conclusion were drawn: 
1. Temperature increment drastically affected the mechanical behavior of the AISI 304 steel. As expected, the mechanical properties declined with an increase in test temperature. However, an abnormal increase in uniform elongation was observed at $50^{\circ} \mathrm{C}$, which is explained by the occurrence of strain-induced martensitic transformation at a wider strain range.

2. The strain-induced transformation was gradually suppressed by the increase in temperature. The temperature in which $\alpha^{\prime}$ martensite ceased to be formed was estimated as being in the 100-125 ${ }^{\circ} \mathrm{C}$ temperature range, although, $\varepsilon$ martensite was still detected. Above this range, no martensite was observed.

3. Fracture surface was found to develop from a mostly flat profile at lower temperature into a serrated profile with V-shaped troughs as the temperature was increased. At lower temperatures, micro-cracks are suppressed by martensitic transformation, resulting in the absence of the V-shaped troughs present at higher temperatures.

4. Dimple morphology presented large round dimples surrounded by a network of smaller dimples at $25^{\circ} \mathrm{C}$ and a combination of finer round and parabolic shear dimples at higher temperatures. This is related to the inhibition of the $\alpha$ ' strain-induced transformation, that reduces the amount of void nucleation sites and dimple nucleation. Additionally, the parabolic shear voids seemingly emerge from in-plane shear plastic fracture occurring between the formed V-shaped troughs.

5. A complex multi-staged strain hardening behavior, typical of metals that present a wide variety of strain hardening mechanisms, was observed at lower temperatures. On the other hand, a more simple behavior was observed at higher temperatures, which is explained by the suppression of the strain-induced martensitic transformation.

6. An anomalous last strain hardening stage, with increasing strain hardening rate and instantaneous strain hardening exponent, was observed at 25 and $50{ }^{\circ} \mathrm{C}$. This was only observed in samples that deformed up to relatively large strains and presented strain induced martensitic transformations.

\section{Acknowledgements}

This work was partially supported by Coordenação de Aperfeiçoamento de Pessoal de Nível Superior (CAPES/ PROEX), Pró-Reitoria de Extensão da Universidade Federal de Minas Gerais (PRPq-UFMG), Conselho Nacional de Desenvolvimento Científico e Tecnológico (CNPq) and
Fundação de Amparo à Pesquisa do Estado de Minas Gerais (FAPEMIG).

\section{References}

1. Rodríguez-Martínez JA, Pesci R, Rusinek A. Experimental study on the martensitic transformation in AISI 304 steel sheets subjected to tension under wide ranges of strain rate at room temperature. Materials Science and Engineering: A. 2011;528(18):5974-5982.

2. Talonen J, Tero T, Hänninen H. Effect of temperature on tensile behaviour and microstructural evolution of nitrogen alloyed austenitic stainless steel. In: Proceedings of the International Conference on High Nitrogen Steels; 2006 Aug 29-31; Jiuzhaigou Valley, Sichuan, China. Jiuzhaigou. p. 52-58.

3. Gonzalez BM, Castro CSB, Buono VTL, Vilela JMC, Andrade MS, Morares JMD, et al. The influence of copper addition on the formability of AISI304 stainless steel. Materials Science and Engineering: A. 2003;343(1-2):51-56.

4. Talonen J. Effect of strain-induced $\alpha$ '-martensite transformation on mechanical properties of metastable austenitic stainless steels [Dissertation]. Espoo: Helsinki University of Technology; 2007.

5. Milad M, Zreiba N, Elhalouani F, Baradai C. The effect of cold work on structure and properties of AISI 304 stainless steel. Journal of Materials Processing Technology. 2008;203(13):80-85

6. Curtze S, Kuokkala VT. Effects of temperature and strain rate on the tensile properties of twip steels. Matéria (Rio de Janeiro). 2010;15(2):157-163.

7. Talonen J, Hänninen H. Formation of shear bands and straininduced martensite during plastic deformation of metastable austenitic stainless steels. Acta Materialia. 2007;55(18):6108-6118.

8. Huang GL, Matlock DK, Krauss G. Martensite formation, strain rate sensitivity, and deformation behavior of type 304 stainless steel sheet. Metallurgical Transactions A. 1989;20(7):1239-1246.

9. Choi JY, Jin W. Strain induced martensite formation and its effect on strain hardening behavior in the cold drawn 304 austenitic stainless steels. Scripta Materialia. 1997;36(1):99-104.

10. Santos TFA, Andrade MS. Internal Friction on AISI 304 Stainless Steels with Low Tensile Deformations at Temperatures between -50 and $20^{\circ} \mathrm{C}$. Advances in Materials Science and Engineering. 2010; 2010:326376.

11. ASTM International. ASTM 37014 Standard Test Methods and Definitions for Mechanical Testing of Steel Products. West Conshohocken: ASTM International; 2014.

12. Inorganic Crystal Structure Database (ICSD). Gmelin-Institut für anorganische Chemie und Fashionformatszetrum. Karlruhe: FIZ; 2007.

13. Jha BK, Avtar R, Dwivedi VS, Ramaswamy V. Applicability of modified Crussard-Jaoul analysis on the deformation behaviour of dual-phase steels. Journal of Materials Science Letters. 1987;6(8):891-893. 
14. Wu ZQ, Ding H, Li HY, Huang ML, Cao FR. Microstructural evolution and strain hardening behavior during plastic deformation of Fe-12Mn-8Al-0.8C steel. Materials Science and Engineering: A. 2013;584:159-155.

15. Jin JE, Lee YK. Strain hardening behavior of a Fe-18Mn0.6C-1.5Al TWIP steel. Materials Science and Engineering: A. 2009;527(1-2):157-161.

16. Jeong K, Jin JE, Jung YS, Kang S, Lee YK. The effects of SI on the mechanical twinning and strain hardening of Fe$18 \mathrm{Mn}-0.6 \mathrm{C}$ twinning-induced plasticity steel. Acta Materialia. 2013;61(9):3399-3410.

17. Xie BS, Cai QW, Yu W, Cao JM, Yang YF. Effect of tempering temperature on resistance to deformation behavior for low carbon bainitic YP960 steels. Materials Science and Engineering: $A$. 2014;618:586-595.

18. Cai M, Ding H, Tang Z, Lee H, Lee Y. Strain Hardening Behavior of High Performance FBDP, TRIP and TWIP Steels. Steel Research International. 2011;82(3):242-248.

19. Toby BH. R factors in Rietveld analysis: How good is good enough? Powder Diffraction. 2006;21(1):67-70.

20. McCusker LB, Von Dreele RB, Cox DE, Louër D, Scardi P. Rietveld refinement guidelines. Journal of Applied Crystallography. 1999;32(1):36-50.

21. Weiß A, Gutte H, Mola J. Contributions of $\varepsilon$ and $\alpha^{\prime}$ TRIP Effects to the Strength and Ductility of AISI 304 (X5CrNi18-10) Austenitic Stainless Steel. Metallurgical and Materials Transactions A. 2016;47(1):112-122.

22. De AK, Speer JG, Matlock DK, Murdock DC, Mataya MC, Comstock Jr. RJ. Deformation-induced phase transformation and strain hardening in type 304 austenitic stainless steel. Metallurgical and Materials Transactions A. 2006;37(6):1875-1886.

23. Rahimi R, Ulrich C, Klemm V, Rafaja D, Cooman BCD, Biermann $\mathrm{H}$, et al. Influence of $\mathrm{Al}$ on the temperature dependence of strain hardening behavior and glide planarity in $\mathrm{Fe}-\mathrm{Cr}-\mathrm{Ni}-\mathrm{Mn}-\mathrm{C}$ austenitic stainless steels. Materials Science and Engineering: A. 2016;649:301-312.

24. Song D, Kang G, Kan Q, Yu C, Zhang C. Multiaxial low-cycle fatigue failure mechanism of super-elastic NiTi shape memory alloy micro-tubes. Materials Science and Engineering: A. 2016;665:17-25.
25. Deformation and fracture mechanisms and static strength of metals. In: Liu AF. Mechanics and Mechanisms of Fracture: An Introduction. Materials Park: ASM International; 2005. p. 47-119.

26. Das A, Tarafder S. Experimental investigation on martensitic transformation and fracture morphologies of austenitic stainless steel. International Journal of Plasticity. 2009;25(11):2222-2247.

27. Sun Y, Li X, Yu X, Ge D, Chen J, Chen J. Fracture Morphologies of Advanced High Strength Steel During Deformation. Acta Metallurgica Sinica (English Letters). 2014;27(1):101-106.

28. Li X, Chen J, Ye L, Ding W, Song P. Influence of strain rate on tensile characteristics of SUS304 metastable austenitic stainless steel. Acta Metallurgica Sinica (English Letters). 2013;26(6):657-662.

29. Yan J, Gao M, Zeng X. Study on microstructure and mechanical properties of 304 stainless steel joints by TIG, laser and laser-TIG hybrid welding. Optics and Lasers in Engineering. 2010;48(4):512-517.

30. Byun TS, Hashimoto N, Farrell K. Temperature dependence of strain hardening and plastic instability behaviors in austenitic stainless steels. Acta Materialia. 2004;52(13):3889-3899.

31. Ferreira PJ, Vander Sande JB, Amaral Fortes M, Kyrolainen A. Microstructure development during high-velocity deformation. Metallurgical and Materials Transactions A 2004;35(10):3091-3101.

32. Choudhary BK, Christopher J. Stage-II tensile work hardening behaviour of type $316 \mathrm{~L}(\mathrm{~N})$ austenitic stainless steel. Materials Science and Engineering: A. 2016;651:486-489.

33. Christopher J, Choudhary BK. Kinetics of Uniaxial Tensile Flow and Work Hardening Behavior of Type 316L(N) Austenitic Stainless Steel in the Framework of Two-Internal-Variable Approach. Metallurgical and Materials Transactions A. 2014;46(2):674-687.

34. Song W, Ingendahl T, Bleck W. Control of Strain Hardening Behavior in High-Mn Austenitic Steels. Acta Metallurgica Sinica (English Letters). 2014;27(3):546-556.

35. Cao Y, Ahlström J, Karlsson B. The influence of temperatures and strain rates on the mechanical behavior of dual phase steel in different conditions. Journal of Materials Research and Technology. 2015;4(1):68-74. 